\title{
RESEARCH
}

Open Access

\section{Prenatal to early postnatal neurotrophic treatment prevents Alzheimer-like behavior and pathology in mice}

Wei Wei ${ }^{1,2+}$, Yifan Wang ${ }^{1 \dagger}$, Yinghua Liu ${ }^{1,3+}$, Chun-Ling Dai ${ }^{1}$, Yunn-Chyn Tung ${ }^{1}$, Fei Liu ${ }^{1}$ and Khalid Iqbal ${ }^{1 *}$

\begin{abstract}
Background: Alzheimer's disease (AD) is a progressive neurodegenerative disorder of middle-aged to old individuals. The pathophysiological process of $A D$ is believed to begin many years before the emergence of clinical symptoms. The important influence of congenital genetic aberrations on the development of AD provides a novel opportunity to initiate prenatal to early postnatal pharmacological treatment to address the role of this critical period of brain development in the disease.
\end{abstract}

Methods: We investigated for the first time the effect of oral treatment during prenatal to early postnatal development with a neurotrophic compound, P021 (Ac-DGGL $\left.{ }^{A} G-N H 2\right)$, on neurobehavior and AD-like pathology in 3xTg-AD, a transgenic mouse model of AD. The transgenic and control wild-type female mice were treated from prenatal day 8 to postnatal day 21 with a custom-made diet containing P021 or a vehicle diet, followed by a standard diet. AD-type cognitive function and pathological features were studied during adulthood and old age.

Results: The P021 treatment rescued cognitive deficits at 4 months, reduced abnormal hyperphosphorylation and accumulation of tau at known major AD neurofibrillary pathology-associated sites, and decreased $A \beta$ plaque load at 22 months in 3xTg-AD mice. Prenatal to early postnatal treatment with P021 also ameliorated certain markers of postsynaptic deficits, including PSD-95 levels and CREB activity, and decreased one measure of neuroinflammation, GFAP level in the brain at 4 and 22 months in 3xTg mice.

Conclusions: These findings suggest that neurotrophic impairment during early development can be one of the etiopathogenic factors of $A D$ and that the neurotrophic peptide mimetic is a potential early prevention strategy for this disease.

Keywords: Alzheimer's disease, Ciliary neurotrophic factor (CNTF)-derived peptide, Cognition, Amyloid- $\beta$, Tau pathology, Neuroplasticity, Neuroinflammation

\footnotetext{
*Correspondence: khalid.iqbal.ibr@gmail.com

${ }^{+}$Wei Wei, Yifan Wang and Yinghua Liu contributed equally to this work. 'Department of Neurochemistry, Inge Grundke-labal Research Floor, New York State Institute for Basic Research in Developmental Disabilities, Staten Island, New York, USA

Full list of author information is available at the end of the article
}

(c) The Author(s). 2020 Open Access This article is licensed under a Creative Commons Attribution 4.0 International License, which permits use, sharing, adaptation, distribution and reproduction in any medium or format, as long as you give appropriate credit to the original author(s) and the source, provide a link to the Creative Commons licence, and indicate if changes were made. The images or other third party material in this article are included in the article's Creative Commons licence, unless indicated otherwise in a credit line to the material. If material is not included in the article's Creative Commons licence and your intended use is not permitted by statutory regulation or exceeds the permitted use, you will need to obtain permission directly from the copyright holder. To view a copy of this licence, visit http://creativecommons.org/licenses/by/4.0/ The Creative Commons Public Domain Dedication waiver (http://creativecommons.org/publicdomain/zero/1.0/) applies to the data made available in this article, unless otherwise stated in a credit line to the data. 


\section{Background}

Alzheimer's disease (AD) is the most common cause of dementia in middle-aged and old individuals, which contributes significantly to health care burden, especially because of the lack of an effective therapy due to its multifactorial and heterogeneous nature and involvement of several different etiopathogenic mechanisms [1, 2]. An estimated 5.7 million Americans suffer from AD; this number includes an estimated 5.5 million people 65 years of age and older, and approximately 200,000 individuals younger than 65 years of age who have the early-onset form of the disease [3]. By 2050, nearly one million new cases are expected to develop per year, and the total estimated prevalence is expected to be 13.8 million [4].

Clinically, AD is characterized by memory deficits, followed by a decline in other cognitive functions $[5,6]$. The two major histopathological hallmarks in the brains of patients with $\mathrm{AD}$ are extracellular senile plaques consisting of amyloid- $\beta$ (A $\beta$ ) peptides [7] and intracellular neurofibrillary tangles (NFTs) composed of abnormally hyperphosphorylated tau protein [8]. Tau pathology is believed to cause neurodegeneration by disrupting the microtubule network and, consequently, axoplasmic transport $[9,10]$. Beta-amyloid plaques are reported to contribute to cell death by interfering with neuron-toneuron communication at synapses [11]. Various inflammatory processes and cytokines may also have a role in the pathology of $\mathrm{AD}$ [12]. Tau and $\mathrm{A} \beta$ pathologies occur several years before the onset of clinical symptoms [13, 14]. After disease onset, it becomes increasingly difficult to treat after neurons start to degenerate, and finely tuned neuronal circuits and cognitive skills are not easily recovered at later stages. Thus, the development of drugs for early prevention and treatment is considered necessary research goals.

Currently, the five FDA-approved drugs available for AD treatment (donepezil, galantamine, rivastigmine, memantine, and donepezil/memantine combination) only provide symptomatic benefit, with little effect on the underlying pathology $[15,16]$. Obviously, there is urgency to find an effective disease-modifying therapy. Thus, a successful therapeutic strategy for AD may include both inhibition of neurodegeneration and stimulation of regeneration of affected areas of the brain.

In AD-transgenic mice, brain-derived neurotrophic factor (BDNF), when administered after disease onset, can reverse synapse loss, partially normalize aberrant gene expression, improve cell signaling, and restore learning and memory $[17,18]$. BDNF exerts substantial protective effects on crucial neuronal circuitry involved in $\mathrm{AD}$, acting through amyloid-independent mechanisms.

During early brain development, neurotrophic factors provide the appropriate brain milieu necessary for all aspects of neural development, including neuronal proliferation, differentiation, growth, and migration [19].
In APP-transgenic mice, BDNF restored the expression of two-thirds of gene sets that were perturbed as a result of mutant APP expression in both the entorhinal cortex and the hippocampus, and learning and memory improved on two separate hippocampus-dependent tasks [17].

Our laboratory generated a 4-mer ciliary neurotrophic factor (CNTF) small molecule peptide mimetic to which adamantylated glycine was added at the C-terminal to generate compound 021 (P021: Ac-DGGL ${ }^{\mathrm{A}} \mathrm{G}-\mathrm{NH} 2$ ), which was found to enhance neuronal proliferation and differentiation by competitively inhibiting leukemia inhibitory factor and by increasing the transcription of BDNF [20-22]. Oral administration of the compound P021 could rescue cognitive aging by enhancing neurogenesis and neuronal plasticity and by decreasing tau levels in aged Fisher rats [20, 21]. Chronic treatment with P021 significantly reduced tau pathology at both the moderate and the severe stages of the pathology in 3xTg-AD mice [23].

The prenatal to early postnatal period is highly susceptible to epigenomic dysregulation with implications for health. Exposure to various environments was shown to induce epigenetic changes and neurodevelopmental deficits and diseases [24]. Stress and hormones, such as glucocorticoids, testosterone, and estradiol, mediate the development of the brain during critical prenatal and early postnatal periods [25]. In a previous study, we found that prenatal to early postnatal treatment with neurotrophic compound P021 rescues developmental delay and at adult age cognitive impairment in a Ts65Dn trisomic Down syndrome mouse model [26]. Maternal choline supplementation and exercise during prenatal period mitigates Alzheimer-like pathology [27, 28].

At present, little information is available on the role of neurotrophins during the early stages of development, which occur during prenatal to early postnatal days (PNDs), on AD later in life. The present study for the first time elucidates the role of prenatal to early postnatal P021 supplementation in preventing the cognitive impairment and major histopathological hallmarks of AD. We found that treatment with P021 from prenatal day 8 till PND 21 prevented cognitive deficits at 4 months, reduced tau and amyloid pathologies at 22 months, and decreased postsynaptic deficits and neuroinflammation in the brain at both 4 and 22 months in 3xTg-AD mice.

\section{Materials and methods \\ Study outline}

Pregnant 3xTg-AD and wild-type (WT) mice were treated with compound P021 in mouse chow, or as control with vehicle feed from gestational day 8 (E8) till their offspring/pups reached PND21, at which point the offspring were separated from their mother and put on 
normal mouse chow (Fig. 1). There were four study groups of mice, as follows: offspring of WT treated with vehicle diet (WT-Vh, $n=10$ ), offspring of WT treated with P021 diet (WT-P021, $n=17$ ), offspring of 3xTg-AD treated with vehicle diet (3xTg-Vh, $n=12)$, and offspring of 3xTg-AD treated with P021 diet (3xTg-P021, $n=18$ ). Elevated plus maze, novel object recognition test, and Morris water maze were carried out consecutively from postnatal day 90 with all of mice. About 50\% (4 animals/ group) of the female offspring ( $n=7-8$ animals/group) were sacrificed at 4 months of age and the remaining $50 \%$ (3-4 animals/group) at 22 months of age. Left cerebral hemisphere homogenate was used for biochemical analysis and right cerebral hemisphere for immunohistochemical studies.

\section{Design and synthesis of P021}

The peptidergic compound P021 (Ac-DGGLAG-NH2; mol. wt. of 578.3) corresponds to a biologically active region of human CNTF (amino acid residues 148-151) to which adamantylated glycine was added at the C-terminal to increase its stability and lipophilicity [29, 30]. The peptide was synthesized and purified by reverse-phase high-performance liquid chromatography to 96\% purity, and the sequence of the peptide was confirmed by mass spectrometry, as described previously [22].

P021 is quite stable in artificial gastric juice ( 90\% during $30 \mathrm{~min}$ ) and in artificial intestinal juice (> 95\% during 120 min). Blood-brain barrier (BBB) studies on P021, which were carried out through a commercial service (APREDI CA, Watertown, MA, USA), demonstrated that enough P021 crossed the BBB to exert its effect in the brain [22].

\section{Animals and housing}

The 3xTg-AD mouse represents one of the most biologically relevant animal models described so far, as it replicates all histopathological and behavioral hallmarks of $\mathrm{AD}$ [31]. The 3xTg-AD mice harbor three AD-related genetic loci: human PS1 M146V, human $\mathrm{APP}_{\mathrm{SWE}}$ $\mathrm{K} 670 \mathrm{M} / \mathrm{N} 671 \mathrm{~L}$, and human tau P301L. These mice display both plaque and tangle pathologies. $A \beta$ deposition is progressive, with intracellular immunoreactivity detected in some brain regions at as early as 3 to 4 months of age. Extracellular A $\beta$ deposits appear by 6 months of age in the frontal cortex and become more extensive by 12 months of age. Changes in tau occur late; by 12 to 15 months of age, aggregates of conformationally altered and hyperphosphorylated tau are detected in the hippocampus. Cognitive impairments first manifest as a retention/retrieval deficit and not as a learning deficit at 4 months of age and occur prior to the occurrence of plaques and tangles [32].

The homozygous 3xTg-AD mice were obtained from Dr. Frank LaFerla (University of California, Irvine, USA) through the Jackson Laboratory (New Harbor, ME, USA). The background of the 3xTg-AD mice is a hybrid $129 / \mathrm{Sv} \times \mathrm{C} 57 \mathrm{BL} / 6$. The non-transgenic WT mice used were from the same strain and genetic background and were also obtained from Jackson Laboratory. Mice were housed and bred in accordance with approved protocols from our Institutional Animal Care and Use Committee and with the PHS Policy on Human Care and Use of Laboratory animals (revised January 2013).

This study was performed on homozygous $3 x \mathrm{Tg}-\mathrm{AD}$ and WT female mice. Female 3xTg-AD mice were chosen because previous studies demonstrated consistent and overt pathology and worse cognitive performance in female than male 3xTg-AD mice [33-35]. Mice were group-housed (four animals per cage) with a 12:12-h light/dark cycle and with ad libitum access to food and water.

\section{Treatment of animals with P021}

We treated 2- to 3-month-old pregnant 3xTg-AD and WT mothers with compound P021 in mouse chow, or

\begin{tabular}{|c|c|c|c|}
\hline \multicolumn{2}{|c|}{$\mid \begin{array}{c}\text { P021 or Vehicle diet } \\
\text { (60nmol } / \mathrm{g} \text { feed })\end{array}$} & \begin{tabular}{|l} 
Normal diet \\
Behavioral \\
evaluation
\end{tabular} & \\
\hline $\begin{array}{l}\text { E8 } \\
\text { 3xTg or WT } \\
\text { pregnant mice }\end{array}$ & 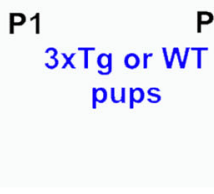 & $\begin{array}{c}\text { P4m } \\
\text { Sacrifice } \\
\text { half female animals } \\
\text { Biochemical study }\end{array}$ & $\begin{array}{c}\mathbf{P 2 2 m} \\
\text { Sacrifice } \\
\text { remaining female animals } \\
\text { Biochemical and } \\
\text { Immunohistochemical studies }\end{array}$ \\
\hline $\begin{array}{l}\text { Fig. } 1 \text { Design of the } \\
\text { postnatal day } 21 \text {, at } v \\
\text { WT-P021 = } 17 ; 3 \times T \text {-V } \\
\text { consecutively from } p \\
\text { animals at } 22 \text { months } \\
\text { hemisphere for imme } \\
\text { Vh, vehicle diet; P021 }\end{array}$ & $\begin{array}{l}\text { study. } 3 \times T g-A D \text { or V } \\
\text { hich time the offsp } \\
\text { eh }=12 ; 3 \times T g-P 021 \\
\text { sstnatal day } 90 \text {. Halt } \\
\text { ( } n=3-4 / \text { group) of } \\
\text { nohistochemical. E\& } \\
\text { peptidergic compc }\end{array}$ & $\begin{array}{l}\Gamma \text { mice were treated with P021 or vehicle diet from gestational } \\
\text { ring were separated from their mothers and put on normal mou } \\
=18 \text { ) were subjected to elevated plus maze, novel object recogn } \\
\text { of the female animals ( } n=7-8 / \text { group) were sacrificed at } 4 \text { mont } \\
\text { age. Left cerebral hemisphere homogenate was used for biocher } \\
\text {, embryonic day } 8 ; \text { P21, postnatal day } 21 ; \text { AD, Alzheimer's diseas } \\
\text { und } 021 \text { diet }\end{array}$ & $\begin{array}{l}\text { day } 8 \text { till their offspring/pups reached } \\
\text { se chow. All of offspring (WT-Veh = 10; } \\
\text { ition test, and Morris water maze test } \\
\text { hs ( } n=4 / \text { group) and the remaining } \\
\text { mical analysis and right cerebral } \\
\text {; } 3 \times \text { Tg, triple-transgenic; WT, wild type; }\end{array}$ \\
\hline
\end{tabular}


with vehicle feed as control at E8 until their offspring/ pups reached PND21, at which point the offspring were separated and put on standard mouse chow (Fig. 1). Treatment was administered as $60 \mathrm{nmol}$ peptide/g formulated diet (Research Diets; New Brunswick, NJ, USA). The vehicle-treated control animals received the same diet but without the peptide. On average, each mouse consumed $\sim 2.7 \mathrm{~g}$ diet/day.

\section{Behavioral procedures \\ Elevated plus maze}

Elevated plus maze was used to evaluate anxiety/emotionality of the mice. It consisted of four arms $(30 \times 5$ $\mathrm{cm})$ connected by a common $5 \times 5 \mathrm{~cm}$ center area. Two opposite-facing arms were open (OA), whereas the other two facing arms were enclosed by $20-\mathrm{cm}$-high walls (CA). The entire plus maze was elevated on a pedestal to a height of $82 \mathrm{~cm}$ above floor level in a room separated from the investigator. Ambient luminosity was maintained at $60 \mathrm{~lx}$ to control the anxiogenic feature of light for rodents. The mouse was placed onto the central area facing an OA and allowed to explore the maze for a single 8-min session. Between each session, any feces were cleared from the maze, and the maze floor was cleaned with $70 \%$ alcohol to remove any urine or scent cues. For each animal, the number of $\mathrm{CA}$ entries, $\mathrm{OA}$ entries, and amount of time spent in CA and OA were automatically recorded by a video.

\section{Novel object recognition test}

The novel object recognition memory task has been used to evaluate hippocampus-dependent memory in rodents through an evaluation of the differences in the exploration time of novel and familiar objects [36]. The testing apparatus was a classic open field (i.e., a PVC square arena, $50 \times 50 \mathrm{~cm}$, with walls $40 \mathrm{~cm}$ high). The open field apparatus was placed in a part of the room separated from the investigator and was surmounted by a video camera connected to a computer. Testing consisted of three different phases: a habituation phase, a sample phase, and a test phase. Following initial exposure, four additional 10-min daily habituation sessions were performed for mice to become familiar with the apparatus $(50 \times 50 \times 40 \mathrm{~cm})$ and the surrounding environment. On the fifth day, every mouse was first subjected to the sample phase, in which two identical objects were placed in a symmetrical position from the center of the arena, and the mouse was allowed to freely explore the objects for $8 \mathrm{~min}$. After a 20-min delay during which the mouse was returned to its home cage, the animal was reintroduced into the arena to perform the test phase. The mouse was then exposed to two objects for another 5 min: a familiar object (previously presented during the sample phase) and a novel object, placed at the same location as during the sample phase. The area of exploration was set to approximately $2 \mathrm{~cm}$ around the object. Data collection was performed using a video tracking system (ANY-maze version 4.5 software; Stoelting Co., Wood Dale, IL, USA). The object discrimination index (DI) during the test phase was calculated as $\mathrm{DI}=[$ (time spent exploring the new object - time spent exploring the old object)/(time spent exploring both old and new objects)] $\times 100 \%$.

\section{Morris water maze}

The Morris water maze task was used to evaluate spatial learning and memory of the mice [37]. A total of 57 mice were subjected to the Morris water maze task at about 4 months of age. The test was performed in a circular white pool (with a diameter of $180 \mathrm{~cm}$ and a height of $60 \mathrm{~cm}$ ) filled with nontoxic white dye-tinted water and maintained at room temperature $\left(20 \pm 1{ }^{\circ} \mathrm{C}\right)$. The maze was designed with two virtual principal axes, with each line bisecting the maze perpendicular to the other one to divide the maze into four equal quadrants. The end of each line demarcated four cardinal points: north, south, east, and west. A platform was positioned in the middle of one of the quadrants submerged $1 \mathrm{~cm}$ below the water surface.

To test the ability of mice to undergo Morris water maze test, a cued test that requires motor strength, ability to see visual cues, swim, and ability to climb the platform was performed $24 \mathrm{~h}$ before the formal experiment. The platform was protruded about $12 \mathrm{~cm}$ from the water surface through a wooden pole, and then the mice were gently placed in the water to sail freely. Those mice that could not swim or climb the platform within $90 \mathrm{~s}$ were eliminated. This cued trial was done only once for each animal.

The Morris water maze test was comprised of two parts: the place navigation test and the spatial probe test. In the place navigation test, each mouse performed four trials for four consecutive days from semi-random start positions to find the hidden platform [38]. Each trial was terminated as soon as the mouse climbed onto the hidden platform. If a mouse failed to find the platform within $90 \mathrm{~s}$, it was gently guided to the platform. At the end of each trial, the mouse was left on the platform for $20 \mathrm{~s}$, then removed, dried, and returned to its home cage. To examine spatial memory, a spatial probe test was administered $24 \mathrm{~h}$ after the last training session. During the probe test, the platform was removed from the pool and the mouse was allowed to swim freely for $1 \mathrm{~min}$.

\section{Tissue processing}

After completion of the behavioral task at postnatal day $120,50 \%$ of the number of female animals ( $n=4$ /group) were perfused, and brain tissue was collected for 
immunohistochemical and biochemical analysis. The remaining female animals continued receiving standard diet and were sacrificed at 22 months of age for immunohistochemical and biochemical analysis.

The animals were anesthetized with an overdose of sodium pentobarbital $(125 \mathrm{mg} / \mathrm{kg})$ and transcardially perfused with $0.1 \mathrm{M}$ phosphate-buffered saline (PBS). After perfusion, the brains were removed from the skull immediately. The left hemisphere was dissected into hippocampus, cerebral cortex, cerebellum, and brain stem; immediately frozen on dry ice; and then stored at $-80^{\circ} \mathrm{C}$ for biochemical analysis.

The complete right hemisphere was immersion-fixed in $4 \%$ paraformaldehyde in $0.1 \mathrm{M}$ PBS for $24-48 \mathrm{~h}$, followed by cryoprotection in a $30 \%$ sucrose solution at $4{ }^{\circ} \mathrm{C}$ overnight. Later, the $40-\mu \mathrm{m}$-thick sagittal sections were cut on a freezing microtome. The sections were stored in glycol anti-freeze solution (ethylene glycol, glycerol, and $0.1 \mathrm{M}$ PBS in 3:3:4 ratio) at $-20^{\circ} \mathrm{C}$ until further processing for immunohistochemical staining.

\section{Immunofluorescence staining and quantification of immunoreactivity}

Immunofluorescence staining was performed on freefloating sections, and every 12th brain section was chosen for densitometry and quantification. For immunohistochemical quantification, six brain sections of four animals per group were analyzed. All stainings for fluorescence-intensity quantification were carried out under identical conditions, including all tissue samples for a particular staining processed at the same time, and experimental and control sections photographed under identical settings. The primary antibodies that were used are described in Table 1. The following secondary antibodies were used: Alexa 488-conjugated goat anti-mouse IgG antibody (1:500, Molecular Probes; Carlsbad, CA, USA) and Alexa 488-conjugated goat anti-rabbit IgG antibody (1:500, Molecular Probes).

\section{Measurement of Thioflavin-S-positive plaque load}

Thioflavin-S-positive (TS+) plaque load was quantified on every 12th section (roughly six sections per set) of four animals from 22-month-old groups. A modified thioflavin-S staining protocol [40] was used as follows. Free-floating brain sections were washed in large volumes of distilled water, incubated in $0.25 \% \mathrm{KMnO}_{4}$ for $4-5 \mathrm{~min}$, washed with water, and treated with a solution of $1 \% \mathrm{~K}_{2} \mathrm{~S}_{2} \mathrm{O}_{5}$ and $1 \%$ oxalic acid for 40-60 s until the brown color was completely washed out. Sections were then incubated with $0.05 \%$ thioflavin-S in water in the dark for $8 \mathrm{~min}$, followed

Table 1 Primary antibodies used in this study

\begin{tabular}{|c|c|c|c|c|c|}
\hline Antibody & Specificity & Species & Type & Dilution & Source \\
\hline $43 \mathrm{D}$ & Total tau & M & Mono- & $0.5 \mu \mathrm{g} / \mathrm{mL} \mathrm{WB}$ & Produced in-house \\
\hline PHF-1 & P-tau (Ser396/404) & M & Mono- & $\begin{array}{l}\text { 1:200 WB } \\
1: 500 \mathrm{IF}\end{array}$ & [39] \\
\hline AT-8 & P-tau (Ser202/T205) & M & Mono- & 1:1000 WB & Thermo Fisher Scientific \\
\hline R134d & Total tau & $\mathrm{R}$ & Poly- & 1:1000 WB & Produced in-house \\
\hline GAPDH & GAPDH & $\mathrm{R}$ & Poly- & 1:1000 WB & Santa Cruz Biotechnology \\
\hline p-APP & Thr668 & $\mathrm{R}$ & Poly- & $1: 1000$ WB & Cell Signaling Technology \\
\hline APP & APP & R & Poly- & $1: 1000$ WB & Generated in our institute \\
\hline Anti-AB & $A \beta / A P P$ & $\mathrm{R}$ & Mono- & $1: 200 \mathrm{IF}$ & Cell Signaling Technology \\
\hline GluR1 & GluR1 & R & Mono- & 1:1000 WB & EMD Millipore \\
\hline Synaptophysin & Synaptophysin & M & Mono- & 1:3000 WB & Millipore \\
\hline SMI 52 & MAP2 & M & Mono- & 1:4000 WB & Sternberger Monoclonals Inc. \\
\hline PSD95 & PSD95 & $\mathrm{R}$ & Poly- & 1: 1000 WB & Cell Signaling Technology \\
\hline NR1 & NMDAR1 & $\mathrm{R}$ & Mono- & 1:500 WB & ABCAM \\
\hline GluR 2/3 & GluR2 + 3 & $\mathrm{R}$ & Mono- & 1:2000 WB & ABCAM \\
\hline Synapsin-1 & Synapsin 1 & $\mathrm{R}$ & Poly- & 1:40000 WB & Enzo Life Sciences \\
\hline CREB & CREB & M & Mono- & 1:1000 WB & Cell Signaling Technology \\
\hline$p$-CREB & Ser133 & $\mathrm{R}$ & Mono- & 1:1000 WB & Cell Signaling Technology \\
\hline |ba-1 & |ba-1 & $\mathrm{R}$ & Poly- & $1: 1000$ WB & Wako Pure Chemical Industries, Ltd. \\
\hline SMI22 & GFAP & M & Mono- & $\begin{array}{l}1: 2000 \mathrm{WB} \\
1: 1000 \mathrm{IF}\end{array}$ & $\begin{array}{l}\text { Sternberger Monoclonals Inc. } \\
\text { (Lutherville, MD,) }\end{array}$ \\
\hline
\end{tabular}

Iba-1 ionized calcium-binding adaptor molecule 1, GFAP glial fibrillary acidic protein, $p$-tau phosphorylated tau, APP amyloid precursor protein, $A \beta$ amyloid- $\beta$, Polypolyclonal, Mono- monoclonal, $R$ rabbit, $M$ mouse 
by differentiation in $80 \%$ ethanol twice for $1 \mathrm{~min}$ each. Sections were then washed three times in distilled water for $1 \mathrm{~min}$ each and mounted by using Fluorgel mounting medium and cover slips (Electron Microscopy Sciences; Hatfield, PA, USA). The images were taken by using a Nikon 90i fluorescent microscope, threshold using ImageJ (v.1.46r), and TS+ plaque load was quantified in the hippocampus CA1 and subiculum areas.

\section{Western blots}

The tissue from the left cerebral hemisphere from each mouse stored at $-80^{\circ} \mathrm{C}$ was homogenized in a Teflonglass homogenizer to generate $10 \%(\mathrm{w} / \mathrm{v})$ homogenate. The pre-chilled homogenization buffer contained 50 $\mathrm{mM}$ Tris- $\mathrm{HCl}$ (pH 7.4), 8.5\% sucrose, $2 \mathrm{mM}$ EDTA, 2 mM EGTA, $10 \mathrm{mM} \beta$-mercaptoethanol plus the following protease and phosphatase inhibitors: $0.5 \mathrm{mM}$ AEBSF, $10 \mu \mathrm{g} / \mathrm{mL}$ aprotinin, $10 \mu \mathrm{g} / \mathrm{mL}$ leupeptin, $4 \mu \mathrm{g} / \mathrm{mL}$ pepstatin, $5 \mathrm{mM}$ benzamidine, $20 \mathrm{mM} \beta$-glycerophosphate, $50 \mathrm{mM}$ sodium fluoride, $1 \mathrm{mM}$ sodium orthovanadate, and $100 \mathrm{nM}$ okadaic acid. Each homogenate was boiled in $2 \times$ Laemmli sample buffer for $5 \mathrm{~min}$, and protein concentration was measured by PierceTM 660-nm protein assay (Thermo Scientific; Rockford, IL, USA).

The samples were subjected to 10\% SDS-PAGE and electro-transferred onto Immobilon-P membranes (EMD Millipore; Billerica, MA, USA). The blots were then probed with primary antibodies (Table 1) and developed with the corresponding HRP-conjugated secondary antibody and enhanced chemiluminescence (Pierce Biotechnology, Rockford, IL, USA). Densitometric quantification of protein bands in Western blots was analyzed using Multi Gauge version 3.0 software (FUJFILM North America; Valhalla, NY, USA).

\section{Statistical analysis}

The statistical analyses were conducted using SPSS version 17.0 (๔ SPSS Inc., 1989-2007; Chicago, IL, USA), SASv5 software (SAS Institute; Cary, NC, USA), and GraphPad Prism version 8.0 (GraphPad Software Inc.; La Jolla, CA, USA). Data are presented as mean \pm S.E.M. The normality of the data was determined by using the Kolmogorov-Smirnov test. For analysis involving multiple groups, three-way or two-way ANOVA followed by Tukey's multiple comparisons test was employed. Further intergroup comparisons were also performed using unpaired two-tailed $t$ tests. For all purposes, $p<0.05$ was considered as statistically significant.

\section{Results}

Prenatal to early postnatal treatment with P021 prevents cognitive deficits at $\sim 4$ months in 3xTg-AD mice In our previous studies, we found that P021 treatment for different periods at young or old age can rescue the cognitive impairment in mice and rats, and both tau and $\mathrm{A} \beta$ pathologies in $3 \mathrm{x}$ Tg-AD mice $[20,23]$. The fact that familial cases of $\mathrm{AD}$, which are caused by certain mutations in APP or presenilin 1 or 2, as well as transgenic mouse models overexpressing these transgenes do not show cognitive impairment and overt pathology till late in adult life led us to investigate the effect of P021 treatment during early development on cognition and $\mathrm{AD}$ pathology at adult age in 3xTg-AD mice. We treated timed pregnant mice at E8 till pups born to them reached PND 21 with P021 in mouse chow or as control vehicle only, followed by standard mouse chow (Fig. 1). At $\sim 4$ months, we studied these animals for any changes in their behavior and pathology.

Anxiety-like behavioral changes are reported to occur in the elevated plus maze task: OA entries, time in OAs, and distance traveled in OAs in AD mice. In this study, we found that in the elevated plus maze test, OA entries, time in OAs, and distance traveled were all significantly decreased in 3xTg-Veh but not in 3xTg-P021 mice. These results suggest that $\mathrm{P} 021$ did not relieve anxietylike behavior in the elevated plus maze task in 3xTg-AD mice (Fig. 2a-c).

To examine whether treatment with P021 could rescue the short-term memory impairment in 3xTg-AD mice, we conducted a one-trial novel object recognition task with a 20-min interval between the sample phase and the test phase. In the one-trial novel object recognition task, each group of mice spent equal amounts of time exploring the two identical objects during the 8-min sample phase (Fig. 2d). After $20 \mathrm{~min}$, the less-explored object during the sample phase was replaced with a novel object during a 5-min test phase. Compared to WT mice, 3xTg-AD mice spent less time exploring the novel object, whereas 3xTg-P021 mice spent a longer time exploring the novel object than did $3 x \mathrm{Tg}-\mathrm{Vh}$ mice (Fig. 2e). These results indicate short-term memory impairment in 3xTg-Vh and its prevention in 3xTg-P021 animals.

To investigate whether treatment with P021 during early development can prevent spatial memory impairment in 3xTg-AD mice, the Morris water maze task was conducted. $3 \times \mathrm{Tg}$-Veh mice showed a noticeable increase in the escape latency during the training days (Fig. 2f), and they also took more time on the first entrance to the target platform and spent less time in the target quadrant than WT mice, whereas in 3xTg-P021 mice, the latency to the first entrance into the target platform was reduced, and the time spent in the target quadrant was similar to that in the WT-Vh mice (Fig. 2g, h). There was no significant difference in the swim speed (Fig. 2i) or cued trial (Fig. 2j) among different groups. Altogether, these results suggest a beneficial effect of P021 treatment during early development in preventing 


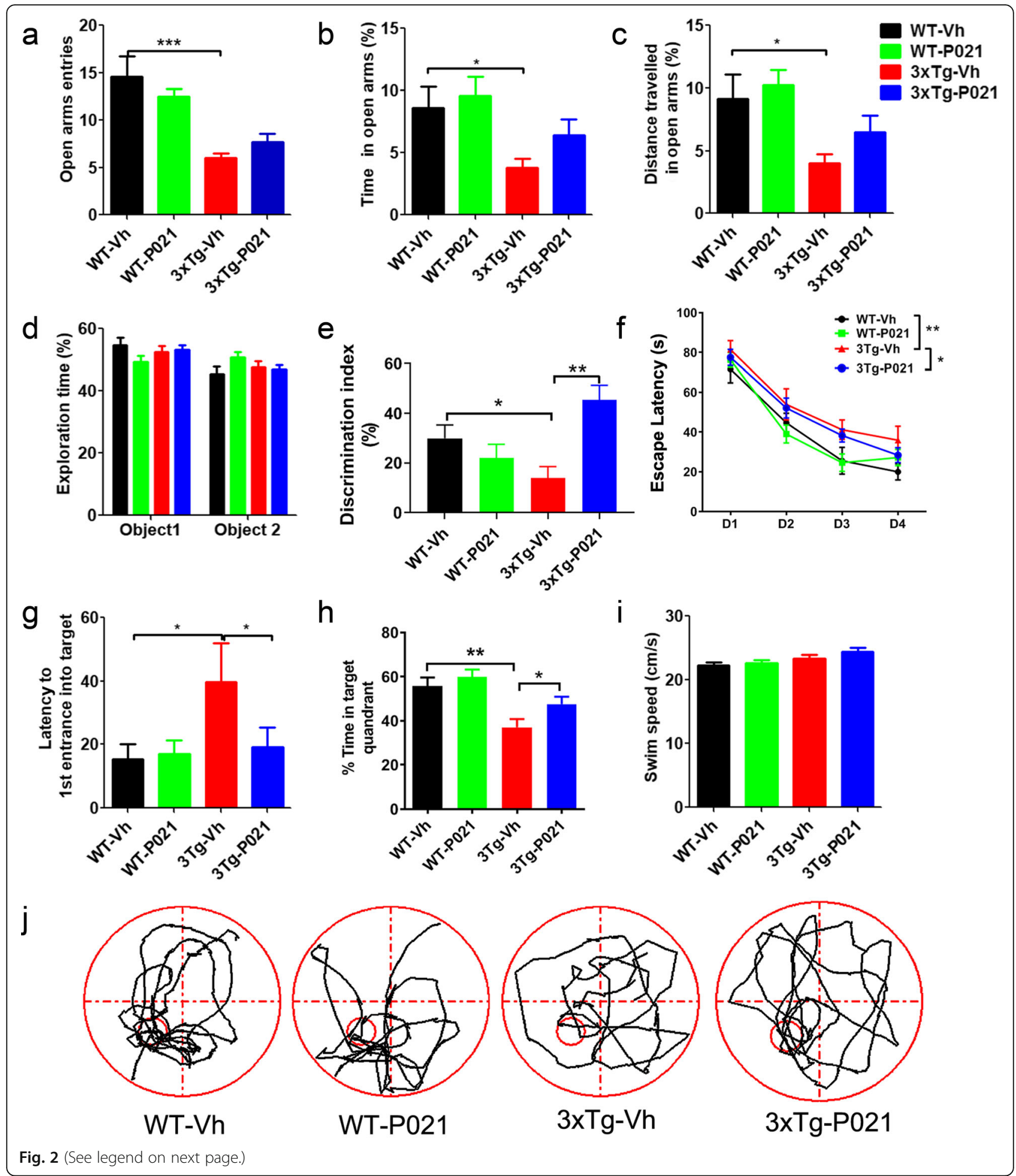


(See figure on previous page.)

Fig. 2 P021 treatment from embryonic day 8 through postnatal day 21 prevents the memory deficits at the age of 3-4 months in 3xTg-AD mice. Elevated plus maze $(\mathbf{a}-\mathbf{c})$, novel object recognition test $(\mathbf{d}, \mathbf{e})$, and Morris water maze $(\mathbf{f}-\mathbf{j})$ were carried out from day 90 to 120 . Decrease in $3 \times \mathrm{Tg}$ Vh mice but not in 3xTg-P021 mice of the number of arm entries (a) (two-way ANOVA, interaction $F(1,50)=2.730 P=0.1048$; treatment $F(1$, $50)=0.03329 P=0.8560$; genotype $F(1,50)=33.15 P<0.0001)$; $\mathbf{b}$ time spent in open arms (two-way ANOVA, interaction $F(1,52)=0.3033 P=$ 0.5842 ; treatment $F(1,52)=1.482 P=0.2289$; genotype $F(1,52)=7.482 P=0.0085$ ); and $\mathbf{c}$ distance traveled in open arms (two-way ANOVA, interaction $F(1,51)=4.500 P=0.0688$; treatment $F(1,51)=0.6570 P=0.4214$; genotype $F(1,51)=30.78 P<0.0001)$. d No difference was observed in the percentage of time spent in exploring two identical objects during the 8-min sample phase (three-way ANOVA, genotypes $\times$ treatments $X$ objects). e A 5-min test phase was carried out 20 min later, and the less-explored object during the sample phase was exchanged with a novel object. Discrimination index (time spent exploring the new object - time spent exploring the old object)/(time spent exploring both old and new objects) $\times 100 \%$ in the test phase was improved in 3xTg-P021 mice (two-way ANOVA, interaction, $F(1,42)=17.46, P=0.0001$; treatment, $F(1$, $42)=3.583, P=0.0653$; genotype, $F(1,42)=0.04287, P=0.8370 ; W T-V h$ vs $3 \times T g-V h P=0.0483 ;$ WT-Vh vs WT-P021 $P=0.3703 ; 3 \times T g-V h$ vs $3 \times T$ Tg-P021 $P=0.0007)$. $f$ During the acquisition phase for 4 days, the escape latency to reach the hidden platform was increased in 3xTg-AD mice compared with WT controls, and treatment with P021 did not prevent it as determined by the three-way ANOVA but showed a clear tendency as determined by the two-tailed $t$ test (three-way ANOVA, days, $F(3,192)=91.77, P<0.0001$; genotype, $F(1,192)=14.86, P=0.0002$; treatment, $F(1$, $192)=2.596, P=0.1088$; two-tailed $t$ tests, WT-Vh vs 3Tg-Vh, $P<0.01 ; 3 x T g-V h$ vs $3 x T g-P 021, P<0.05)$. $g$ In the probe trial, $3 x T g-A D$ mice took more time in the first entrance into the target zone, and treatment with P021 decreased the latency significantly (two-way ANOVA, interaction $F$ $(1,59)=6.324 P=0.0147$; treatment $F(1,59)=3.634 P=0.0615$; genotype $F(1,59)=4.601 P=0.0361$; WT-Vh vs $3 \times \operatorname{Tg}$-Vh $P=0.0095$; WT-Vh vs WTP021 $P=0.9737 ; 3 x T g-V h$ vs 3xTg-P021 $P=0.0132)$. h 3xTg-AD but not 3xTg-AD-P021 mice spent less time in the target quadrant than did WT mice (two-way ANOVA, interaction $F(1,56)=0.8808 P=0.3520$; treatment $F(1,56)=6.928 P=0.0109$; genotype $F(1,56)=22.64 P<0.0001$; WT-Vh

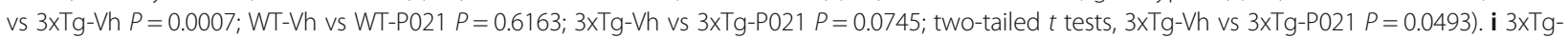
AD mice and WT controls displayed similar swim speed. $\mathbf{j}$ Cued trial, examples of swim path to the cued platform; all animals found the cued platform. $n=10$ for WT-Vh; $n=17$ for WT-P021; $n=12$ for $3 \times$ Tg-Vh and $n=18$ for $3 \times$ Tg-P021. ${ }^{*} P<0.05,{ }^{* *} P<0.01,{ }^{* * *} P<0.001$

certain measures of cognitive impairment in $3 \times \mathrm{Tg}-\mathrm{Vh}$ mice.

\section{Prenatal to early postnatal treatment with P021 prevents tau pathology at 22 months in 3xTg-AD mice}

To determine the effect of treatment with P021 during early development on tau pathology in the hippocampus of $3 x \mathrm{Tg}$ mice at different ages, we performed Western blots and immunohistofluorescence staining to study changes in the levels and expressions of total and hyperphosphorylated taus. We found that compared with agematched WT-Vh mice, 4-month-old 3xTg-Vh mice exhibited a significant increase in total tau detected with antibody R134d. P021 treatment decreased the total tau detected with R134d and human-specific tau with antibody 43D (Fig. 3A, C). There was no increase in hyperphosphorylation of tau in 4-month-old 3xTg-Vh mice as compared to the WT control mice. Nevertheless, the P021 treatment was found to decrease the level of tau hyperphosphorylation at Ser202/Thr205 detected with antibody AT8 in 4-month-old 3xTg-AD mice.

In 22-month-old mice, we found an increase in total tau level with antibody R134d and an increase in tau hyperphosphorylation at Ser-396/404 detected with antibody PHF-1, and at Ser202/Thr205 detected with antibody AT8 in 3xTg-Vh compared with WT-Vh. P021 treatment decreased tau hyperphosphorylation both at PHF-1 and AT8 sites, whereas there was only an insignificant decrease in total tau in P021-treated animals; levels of human tau detected with antibody 43D and hyperphosphorylated tau detected with antibody pT212, however, did not change significantly (Fig. 3B, D). To further evaluate changes in hyperphosphorylated tau in 22-month-old mice, we performed PHF-1 immunofluorescence and found a significant increase in the hippocampal CA1 region of $3 \times \mathrm{Tg}-\mathrm{Vh}$ mice, whereas it was attenuated in 3xTg-AD-P021 mice (Fig. 3E, F). Altogether, the above data indicate that prenatal to early postnatal treatment with P021 can prevent tau pathology in the hippocampus of 3xTg mice at 22 months of age.

\section{Prenatal to early postnatal treatment with $\mathrm{P} 021$ reduces amyloid plaques and A $\beta / A P P$ levels at 22 months in $3 \times \mathrm{Tg}$ mice}

Amyloid plaques are developed in 3xTg-AD mice starting at around 6-9 months of age, and they are first observed in the cerebral cortex and progress to the hippocampus with age [31]. To evaluate the effect of P021 on A $\beta$ pathology at 22 months of age in 3xTg mice, we performed A $\beta$ immunofluorescence in the serial coronal sections of one half of the brain dissected through the midline. Amyloid plaques detected by $A \beta$ antibody were found to be widely distributed in the subiculum, piriform cortex, forebrain, and hippocampus of 3xTg mice (Fig. 4A, a-d), and the plaques in the same regions were markedly reduced in 3xTg-AD-P021 mice (Fig. 4A, e-h), whereas no plaques were observed in the brains of age-matched WT mice. Moreover, the plaque-occupied area was significantly decreased in 3xTg-P021 mice (Fig. 4D). To confirm the changes in $A \beta$ plaque load, we also performed thioflavin-S staining and found that the plaque burden increased predominately in the subiculum of $3 \mathrm{xTg}-\mathrm{Vh}$ mice, whereas 3xTg-P021 mice showed a significant decrease (Fig. 4B, E). Correspondingly, Western blots showed that the level of phosphorylation of APP at Thr668 was elevated significantly in the hippocampus of 3xTg-Vh mice, and it was 


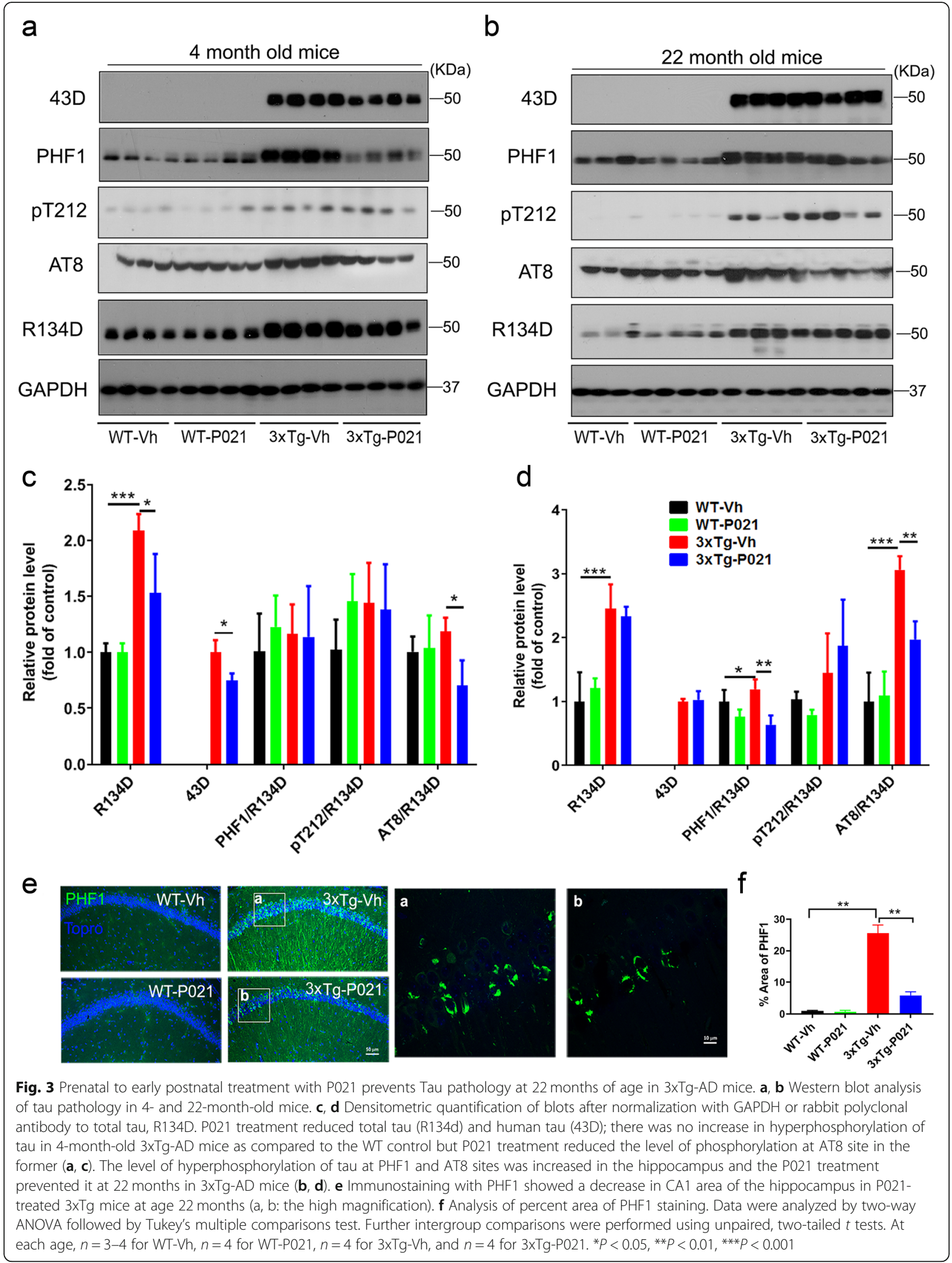


a
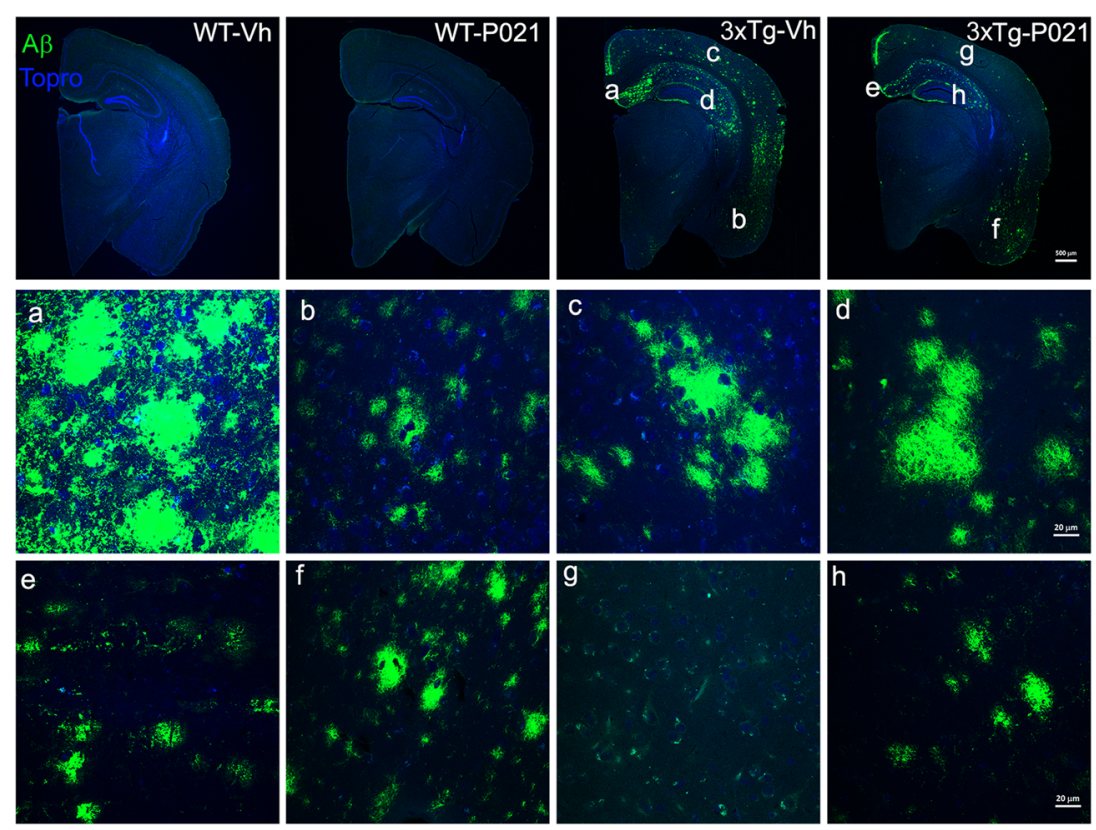

b
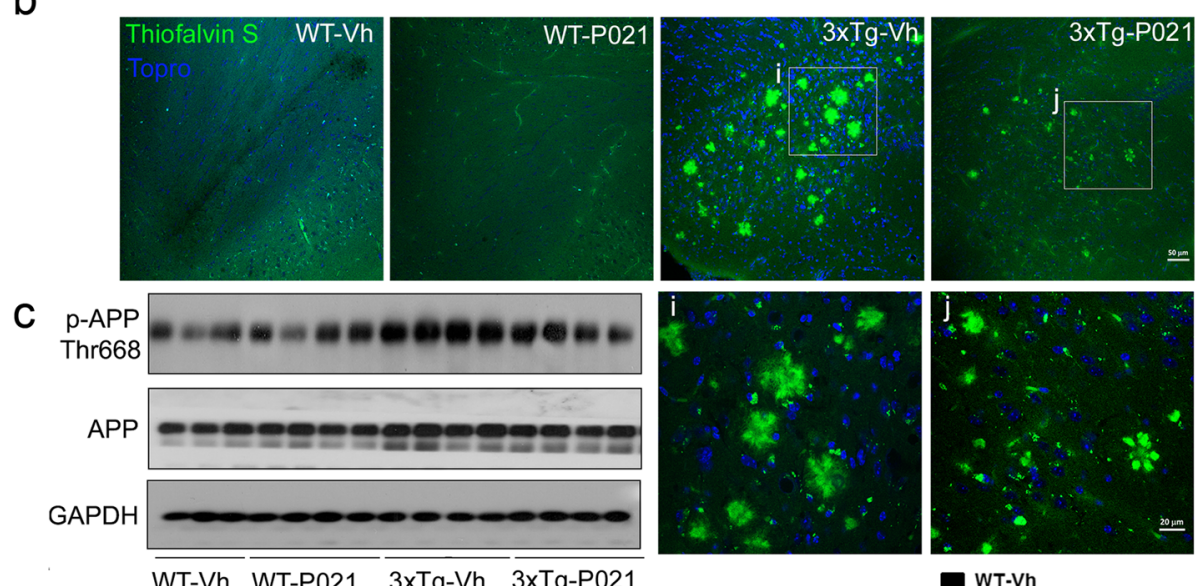

d
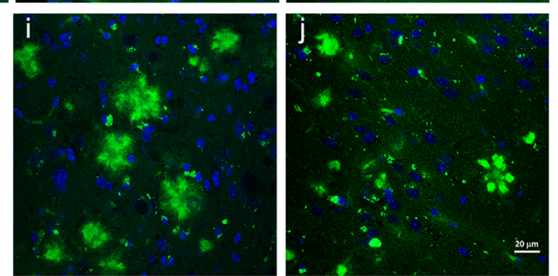

WT-Vh WT-P021 3xTg-Vh 3xTg-P021

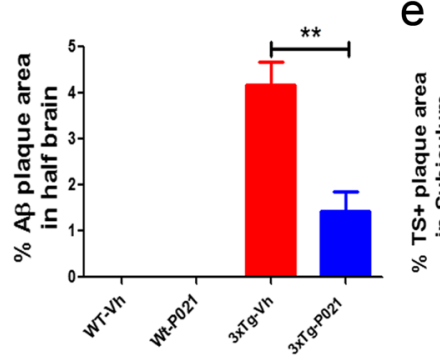

e

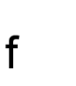

WT-Vh

WT-P021

B. $3 \times 1 \mathrm{Tg}-\mathrm{Vh}$
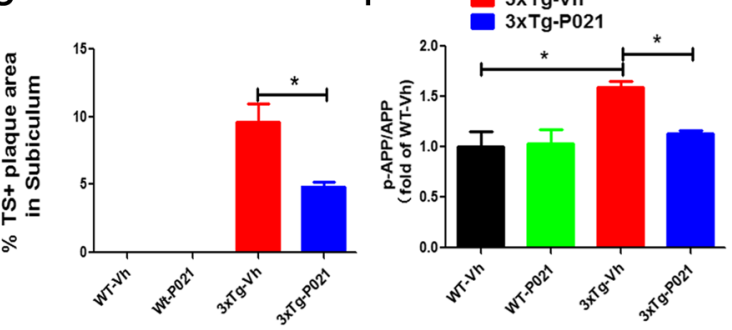

Fig. 4 Prenatal to early postnatal treatment with P021 prevents A $\beta$ pathology in 22-month-old 3xTg-AD mice. a A immunofluorescence in the coronal brain sections of one half of the brain ( $\mathrm{a}-\mathrm{h}$ : the high magnification, $\mathrm{a}$ and e for the subiculum, $\mathrm{b}$ and $\mathrm{f}$ for the piriform cortex, $\mathrm{c}$ and $\mathrm{g}$ for the forebrain, $\mathrm{d}$ and $\mathrm{h}$ for the hippocampus). $\mathbf{b}$ Thioflavin-S staining in the subiculum region in 3xTg-AD mice ( $i$ and $\mathrm{j}$ : the high magnification for the subiculum). c Representative Western blots of the hippocampus developed with antibodies to p-APP or APP. Quantification of the A staining area in one half of the brain ( 6 sections per mouse, $n=4$ mice). $\mathbf{d}$ Amyloid plaque area seen by immunofluorescence in one half of the brain. e Amyloid plaque area detected by thioflavin- $S$ staining in the subiculum ( 6 sections per mouse, $n=4$ mice). $\mathbf{f}$ Relative level of phosphorylation of APP at Thr 668 after normalization with GAPDH $(n=4)$. Data were analyzed by two-way ANOVA followed by Tukey's multiple comparisons test. Further intergroup comparisons were performed using unpaired, two-tailed $t$ tests. ${ }^{*} P<0.05,{ }^{* *} P<0.01$ 
rescued in 3xTg-P021 animals (Fig. 4c, f). Collectively, these results revealed that $\mathrm{P} 021$ treatment during early development could prevent $A \beta$ plaque pathology during old age in $3 \times \mathrm{Tg}$ mice.

\section{Prenatal to early postnatal treatment with P021 ameliorates the neuroplasticity related glutamate receptor and postsynaptic deficits and increases CREB activity in 3xTg-AD mice}

Synaptic deficit is a feature of AD pathology. The glutamate receptors AMPA ( $\alpha$-amino-3-hydroxy-5-methyl-4-isoxazole propionic acid) and NMDA ( $N$-methyl$\mathrm{D}$-aspartate) receptors play essential roles in synaptic transmission and long-term potentiation (LTP) as well as cellular mechanisms that are associated with learning and memory $[41,42]$. Our previous studies showed that synaptic deficit could be rescued by chronic P021 treatment in adult 3xTg-AD mice [43, 44]. Herein we examined whether the synaptic changes at adult age could be affected by treatment with P021 during a period of early development. At 4 months of age, the level of GluR1 was significantly reduced in $3 \times \mathrm{Tg}-\mathrm{Vh}$ mice compared with WT-Vh mice, and after P021 treatment, not only GluR1 but also levels of NR1, NR2A, and phosphorylated CREB (p-CREB) were increased, whereas no significant changes in NR2B and GluR2\&3 were found among groups (Fig. 5a, c). At 22 months, we found that levels of NR1, NR2A, and p-CREB were increased in the hippocampus of 3xTg mice with P021 treatment, but no significant changes in NR2B, GluR1, GluR2, and 3 were observed among these groups (Fig. 5b, d).

Synaptic loss is known to be correlated with cognitive decline in $\mathrm{AD}[45,46]$. We therefore studied whether treatment with P021 during early development can ameliorate deficits in markers of dendritic and synaptic plasticity in 3xTg-AD mice at different stages of the disease. We found that levels of PSD95, synapsin, synaptophysin, and MAP2 were all notably decreased in 3xTgVh mice, but only the PSD 95 deficit was rescued in 3xTg-P021 animals, suggesting an important role of PSD 95 in cognitive function in 3xTg mice (Fig. 6a, c). While no significant changes in levels of PSD95, synapsin, synaptophysin, and MAP2 were found between $3 \times \mathrm{Tg}$ and WT mice at 22 months of age, there was a trend for an increase in these levels in 3xTg-P021 mice (Fig. 6b, d).

Prenatal to early postnatal treatment with P021 prevents neuroinflammation at 4 and 22 months in $3 \times T g$ mice

Microglia and astrocytes are the most abundant cell types in the brain and are instrumental in supporting neuronal health and function. However, microgliosis and astrogliosis can also be major contributors to chronic neuroinflammation that diminishes neuronal integrity, and they contribute to neurodegeneration in tauopathies
[47, 48]. Glial fibrillary acidic protein (GFAP) plays an important role in brain inflammation and in mediating astrocyte-neuron interactions [49]. In a previous study, we found that P021 can stimulate the expression of GFAP [20]. In the present study, we investigated expressions of Iba-1 (a microglial marker) and GFAP in the hippocampus by Western blots and immunofluorescence. We detected no significant changes in expression of Iba- 1 among groups at both 4 and 22 months (Fig. 7a, b), whereas GFAP was significantly increased in the $3 \times \mathrm{Tg}-\mathrm{Vh}$ mice at 4 and 22 months, and this increase was rescued in 3xTg-P021 animals (Fig. 7a, b). Additionally, GFAP immunoreactivity was also highly elevated in the CA1 region of $3 \times \mathrm{Tg}-\mathrm{Vh}$ mice and was rescued in $3 \mathrm{xTg}$ P021 animals (Fig. 7c, upper panel). Moreover, at high magnification, astrocytes in $3 \mathrm{xTg}-\mathrm{Vh}$ mice were amoeboid and showed large cell body and shorter processes (an advanced activated phenotype), whereas astrocytes in 3xTgP021 mice appeared ramified with long processes and small cell body (resting phenotype) (Fig. 7c, lower panel). These findings suggested that treatment with P021 during early development can prevent certain components of neuroinflammation involving astrocytes in the hippocampus of $3 x \operatorname{Tg}$ mice.

\section{Discussion}

The present study shows for the first time that prenatal to early postnatal treatment with the neurotrophic compound P021 can prevent not only cognitive deficit but also AD-type pathological changes, which include tau and $A \beta$ pathologies, postsynaptic deficit, and neuroinflammation later in life in 3xTg mice. These findings suggest the novel concept that $\mathrm{AD}$ can be a developmental disability with a late-life phenotype and that adjusting the brain molecular milieu by providing appropriate neurotrophic support at a critical period of brain development can be an effective therapeutic strategy for the prevention of $\mathrm{AD}$ and related conditions later in life.

Neural tube formation occurs approximately midgestation in rodents, on E 10.5-11 and 9-9.5 in rats and mice, respectively, with birth typically occurring on E20-21 [50, 51]. The mouse cortex reaches approximately $90 \%$ of its adult weight by postnatal day 20 , the typical age of weaning in rodents. In humans, brain weight reaches a similar plateau by 2-3 years of age. Thus, based on brain weight alone, postnatal day 21 in mice appears to correspond to 2- to 3-year-old humans [52]. The expression of pro-BDNF peaks on postnatal day 15 and declines in later stages, whereas the expression of mature BDNF peaks on postnatal day 21 and stays high in adulthood in mice [53]. Although there is no evidence that neurotrophic factors are reduced during early brain development in $\mathrm{AD}, \mathrm{BDNF}$ deficit has been reported in Down syndrome during early 

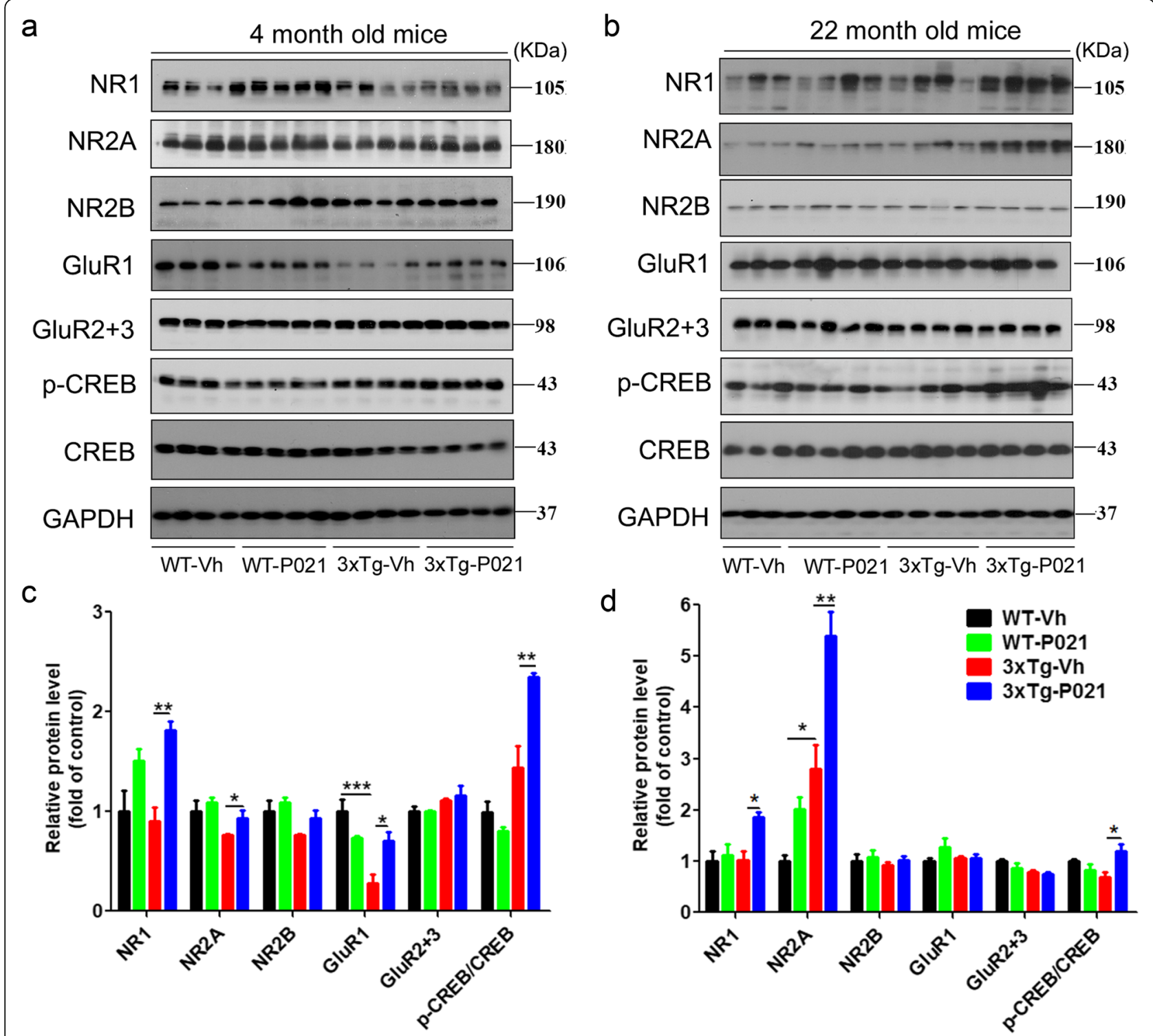

Fig. 5 Prenatal to early postnatal treatment with P021 prevents dendritic deficits and increases CREB activity at 4 months and 22 months of age in $3 \times$ TgAD mice. $\mathbf{a}$, b Representative Western blots of the hippocampus for NR1, NR2A, NR2B, GluR1, GluR2\&3, p-CREB, CREB, and GAPDH at 4 months and 22 months in P021- or vehicle-treated mice. $\mathbf{c}$, d Densitometric quantification of the above proteins after normalization with GAPDH. 3xTg-Vh mice showed a marked decrease of GluR1, while P021 treatment increased the levels of NR1, NR2A, GUR1, and p-CREB significantly at 4 months of age. At 22 months, P021 elevated the levels of NR1, NR2A, and p-CREB in 3xTg-AD mice. $\mathbf{d}$ Data were analyzed by two-way ANOVA followed by Tukey's multiple comparisons test. Further intergroup comparisons were performed using unpaired, two-tailed $t$ test. $n=3-4$ animals/group. ${ }^{*} P<0.05$, ${ }^{* *} P<0.01$, ${ }^{* * *} P<0.001$

development [54, 55]; Down syndrome is a developmental disability that develops AD pathology during the fourth decade of life [56]. We hypothesized that diseasecausing mutations in APP, PS1, and tau could affect the neurotrophic milieu during the early development period. Toward this hypothesis, we treated the timed pregnant 3xTg-AD mice at E8 until the pups that were born to them reached PND 21 with P021 in mouse chow. Thus, pups received P021 through the placenta till birth and then from mother's milk till weaning and separation from the mother on PND 21; around PND 15-
18 , pups also start nibbling on chow that is dropped in the cage.

A central objective of the field of dementia research is to inhibit, or to at least effectively modify, the course of $\mathrm{AD}$, but at present, no effective treatment or cure for $\mathrm{AD}$ is available. CNTF is a pluripotent neurotrophic factor that has a potent effect on the development and maintenance of the nervous system, inducing neuronal survival and differentiation by stimulating gene expression of sensory, sympathetic, and motor neurons [57]. However, the clinical therapeutic usage of recombinant 


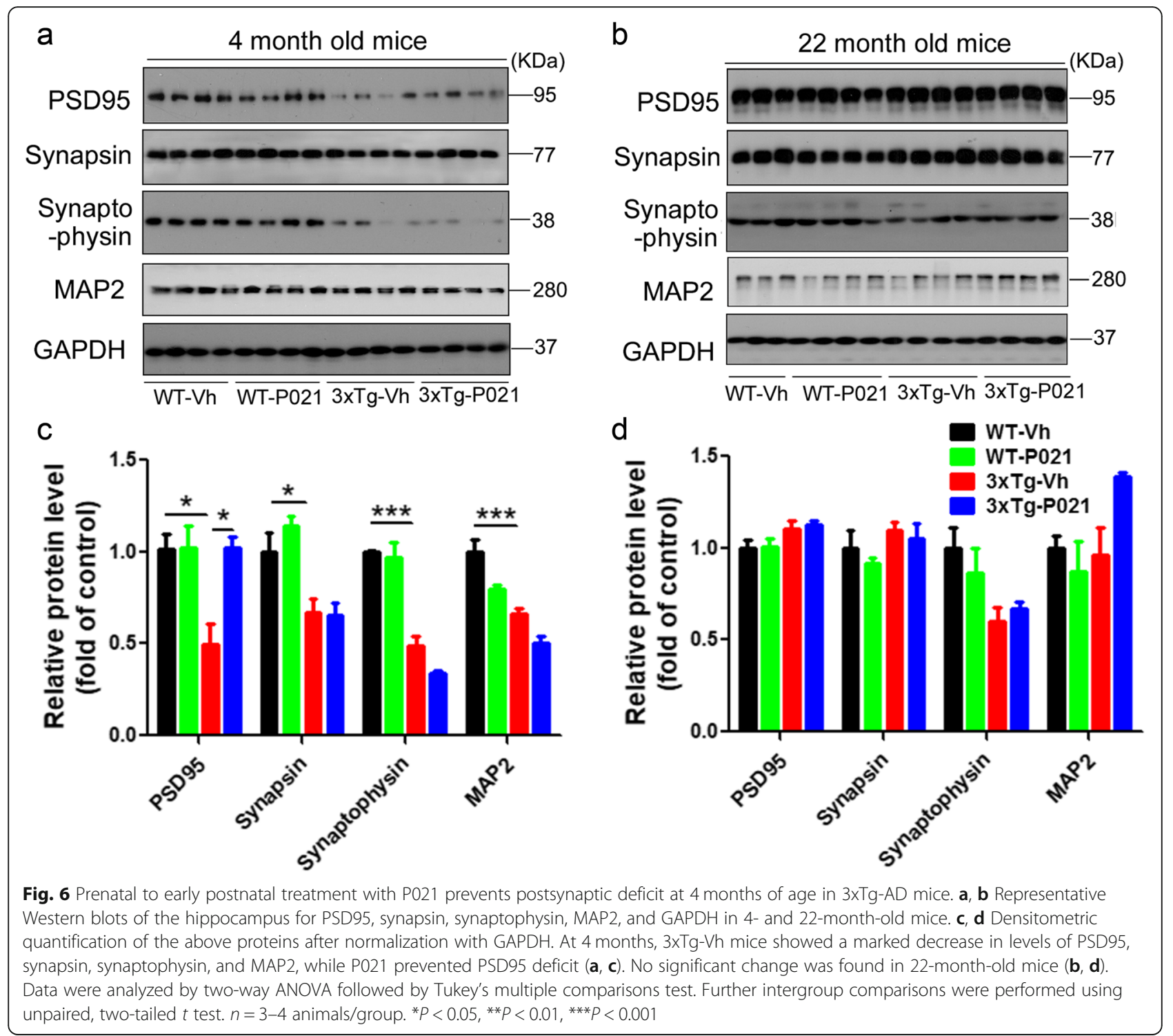

neurotrophic factors is limited because of the insurmountable hurdles of unfavorable pharmacokinetic properties, poor BBB permeability, and severe adverse effects [58]. P021, which was generated in our laboratory, is a small water-soluble compound, is BBBpermeable, has suitable pharmacokinetic properties for oral administration, and does not induce the systemic adverse effects associated with recombinant CNTF or $\operatorname{BDNF}[21,23,59]$. P021 was shown to rescue cognitive impairment in rodent models of $\mathrm{AD}$ via increased $\mathrm{BDNF}$ expression [20, 23, 54]. Treatment with P021 during prenatal till early postnatal development was found to rescue developmental delay and $\mathrm{AD}$-like hippocampusdependent cognitive impairments in adult mice with Down syndrome [26]. In the present study, P021 administered orally to mouse mothers during gestation and weaning of their offspring apparently reached significant amounts in the offspring's brain to exert beneficial effect on cognitive performance, probably via increased NR1, NR2A, and CREB expression, by rescue of the PSD95 deficit and prevention of tau and $A \beta$ pathologies.

$\mathrm{AD}$ is a pathological process that starts in mid-life but remains undetected until it causes dementia, at which time a clinical diagnosis of $\mathrm{AD}$ dementia can be made. Recent revisions to diagnostic criteria define three stages of $\mathrm{AD}$, namely preclinical $\mathrm{AD}$ [60], mild cognitive impairment due to $\mathrm{AD}$ (MCI-AD) [61], and $\mathrm{AD}$ dementia [62]. Meanwhile, the $3 \times \mathrm{Tg}$-AD mouse model manifests cognitive impairment at 4 months as a deficit in longterm retention, but develops $A \beta$ accumulation at approximately 6-9 months of age, and tau pathology starting at a slightly later age $[29,63]$. Because $\mathrm{AD}$ patients as well as transgenic mouse models of $\mathrm{AD}$ have a long preclinical stage that can last for several decades 


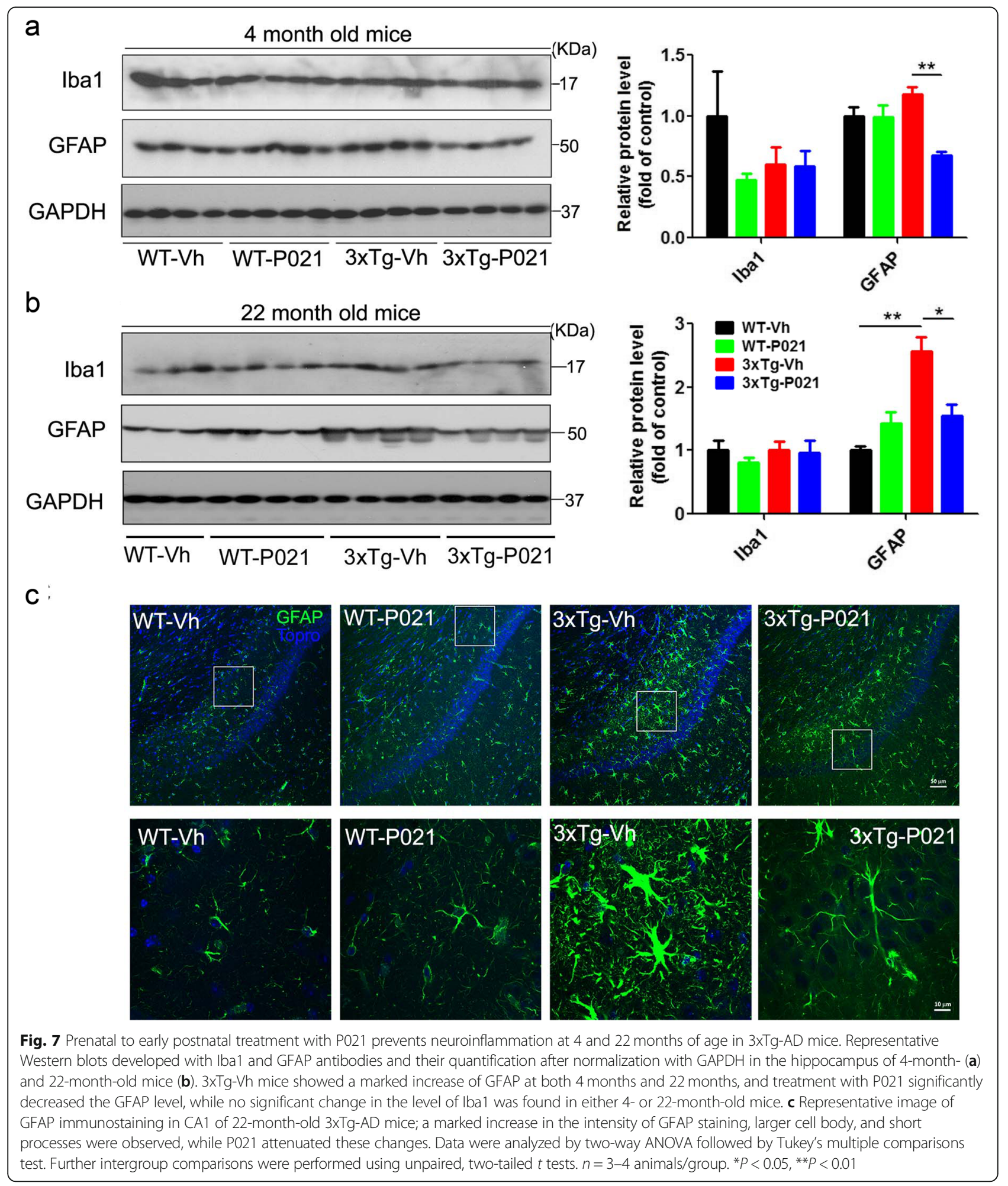

in humans, it is meaningful to investigate the preventive effect of intervening at the earliest stages of $\mathrm{AD}$. The present study shows that prenatal to early postnatal treatment with P021 can significantly prevent both tau and $\mathrm{A} \beta$ plaque pathologies in adult $3 \times \mathrm{Tg}$ mice.
Previously, we showed that P021 increases the transcription and expression of BDNF in mice and rats $[1,20,23$, $26,44,58]$. The beneficial therapeutic effect of P021 apparently involves the increase in the expression of BDNF, which via the TrkB-PI3K-AKT pathway leads to 
inhibitory phosphorylation of GSK3 $\beta$ at Ser9 [23]. And the inhibition of GSK3 $\beta$ in turn prevents abnormal hyperphosphorylation of tau at several major sites and through reduction of phosphorylation of APP at Thr 668 its amyloidogenic processing and $A \beta$ pathology [58].

$\mathrm{AD}$ has been characterized as a synaptic failure [64]. Synapse loss is an early feature of AD, and there is a strong correlation between the severity of dementia and the extent of synaptic loss. Accordingly, it has been proposed that synaptic loss underlies the memory impairment evident in the early phase of $\mathrm{AD}$ and that since plasticity is important for neuronal viability, persistent disruption of plasticity may account for the frank cell loss typical of later phases of the disease [32, 65, 66]. Synaptic dysfunction, including LTP deficit, occurs prior to overt plaque and tangle pathologies in $3 \times \mathrm{Tg}-\mathrm{AD}$ mice [62]. In the present study, we observed a significant reduction in the density of the presynaptic markers synapsin and synaptophysin, dendritic marker MAP2, and postsynaptic marker PSD95 at 4 months. This dendritic and synaptic loss may lead to deficit in synaptic plasticity. We found that treatment with P021 from prenatal to early postnatal development can prevent synaptic loss, as evidenced by rescue of PSD 95 level. These findings led us to speculate that treatment with P021 during early development probably ameliorates the changes in homeostasis of brain milieu and provides an optimal microenvironment for neuronal proliferation and synaptogenesis and thus enhanced neuronal plasticity. Deficits in synaptic markers were found at age 4 months but not at 22-month 3xTg-AD mice. The exact reason for this apparent discrepancy is, at present, not known and will have to be investigated in future studies. Apparently, like in $\mathrm{AD}$, the synaptic degeneration is quite marked and precedes tau and Abeta pathologies in 3xTg-AD mice. At 22 months, we speculate, there are also age-associated losses in synaptic markers and the differences, especially in presynaptic markers between $3 \times \mathrm{Tg}-\mathrm{AD}$ and their genetic background-matched control animals, are probably inconsistent and below the detection limit.

Neuroinflammation has been described as an important contributor to $\mathrm{AD}$ pathogenesis and cognitive decline [12, 67]. Neuroinflammation is also seen in 3xTg-AD mice [68]. In the present study, we found astrogliosis can be prevented by treatment with P021 during early development in 3xTg-AD mice. Neuroinflammation in $3 \mathrm{xTg}-\mathrm{AD}$ mice has been shown to involve $\mathrm{A} \beta$ and tau pathologies [69]. It is thus possible that treatment with P021 during early development, by virtue of its effect on $A \beta$ and tau pathologies, normalizes the neuroinflammation in $3 \mathrm{xTg}-\mathrm{AD}$ mice, which in turn contributes to the beneficial effect of P021 on neuronal and synaptic deficits, and cognition.
Although this study provided a proof of principle of the beneficial effect of prenatal to early postnatal treatment with P021 on prevention of cognitive impairment and $\mathrm{AD}$-like pathological changes, it lacks information on the level of the compound that reached the brain in fetuses and pups during various stages of development. A dosing study employing the direct administration of P021 to the pups and analysis of the level of the compound in the brain in fetuses and pups remains to be conducted. Another major limitation of the study is that it did not determine whether the beneficial effect of the P021 treatment is due to this treatment during the prenatal or the postnatal period, or both. It is not known if there is any neurotrophin deficit, whether related to CNTF, BDNF, or other neurotrophins, during development in the AD model used in the present study. Thus, it remains to be investigated in future studies whether the treatment here is making up for a deficit, or alternatively, there is no deficit promoting eventual $\mathrm{AD}$ pathology but the further increase in neurotrophin-related mechanisms is nevertheless introducing a protective or preventative function. From the present study, we also not know whether the beneficial effects of P021 are simply through the reduction of tau or $A \beta$ pathologies or neuroinflammation or increase in one or more neuronal plasticity-related mechanisms or having multiple direct effects. The present study used only female AD mice for biochemical studies. Thus, another important information which must await future studies is whether both male and female gender will benefit equally from neurotrophic treatment during the period of early development.

The 3xTg-AD mouse model though faithfully reproduces characteristic features of $\mathrm{AD}$, i.e., cognitive impairment and neurodegeneration associated with $A \beta$ plaques and neurofibrillary pathology of hyperphosphorylated tau, the underlying disease mechanism in this triple-transgenic model which incorporates two APP and one presenilin-1 AD and one tau frontotemporal dementia mutations is probably very different from human AD. However, the beneficial therapeutic effect of P021 we found in previous studies in aged mice and rats, Ts65Dn trisomic Down's mice, and in a rat model of protein phosphatase inhibition suggests the therapeutic potential of this compound. Double-blind placebocontrolled human clinical trials of this compound for various neurodegenerative conditions will be required to understand its potential for human use.

\section{Conclusions}

The present study shows that prenatal to early postnatal treatment with the neurotrophic compound P021 in 3xTg-AD mice can not only prevent certain cognitive deficits, possibly in part via the increase in the activity of CREB and levels of glutamate receptors and rescue of 
PSD95 associated synaptic deficit, but also ameliorate selected pathological hallmarks, including $A \beta$ plaque and tau pathologies and astrocyte-related markers of neuroinflammation.

\section{Abbreviations}

AD: Alzheimer's disease; AKT: Protein kinase B; AMPA: a-Amino-3-hydroxy-5methyl-4-isoxazolepropionic acid; APP: Amyloid precursor protein; $A \beta$ : Amyloid- $\beta$; BDNF: Brain-derived neurotrophic factor; CNTF: Ciliary neurotrophic factor; CA: Closed arm; CREB: CAMP response element-binding protein; E: Gestational day; GAPDH: Glyceraldehyde 3-phosphate dehydrogenase; GFAP: Glial fibrillary acidic protein; GluR: Glutamate receptor; LTP: Long-term potentiation; MCI-AD: Mild cognitive impairment due to AD; MWM: Morris water maze; NFTs: Neurofibrillary tangles; NMDA: N-Methyl-Daspartate acid; NR: N-Methyl-D-aspartate receptor; NOR: Novel object recognition; OA: Open arm; P021: Peptidergic compound 021, Ac-DGGL ${ }^{A} G-$ $\mathrm{NH2}$; PHF: Paired helical filament; PI3Ks: Phosphoinositide 3-kinases; PND: Postnatal day; PSD95: Postsynaptic density protein 95; pS199: Phosphotau (Ser199); pT205: Phospho-tau (Thr205); 3xTg: Triple-transgenic TrkB: Tropomyosin receptor kinase B; TS: Thioflavin-S; WT: Wild type

\section{Acknowledgements}

We are thankful to Dr. Peter Davies for his generous gift of tau monoclonal antibody PHF-1, Dr. Wen Hu for valuable guidance in photographing and preparing the images and conducting statistical analyses, and Ms. Maureen Marlow for copyediting the manuscript.

\section{Authors' contributions}

W. Wei carried out the study and wrote the paper. Y. F. Wang treated the animals. Y. Liu studied the immunofluorescence and analyzed the data. C.L. Dai treated the animals. Y.C. Tung performed the Western blots. F. Liu helped in discussing the data and writing the paper. K. Iqbal conceived, designed, and supervised the study and wrote the paper. The authors read and approved the final manuscript.

\section{Funding}

This work was supported in part by the New York State Office for People With Developmental Disabilities (OPWDD) and the State Scholarship Fund of China (No. 201608440026 and No. 201606785014).

\section{Availability of data and materials}

The datasets generated and/or analyzed during the present study are available from Dr. Wei Wei through the corresponding author upon reasonable request.

\section{Ethics approval and consent to participate}

All procedures involving mice were reviewed and approved by the Institute for Basic Research in Developmental Disabilities Institutional Animal Care and Use Committee and were carried out according to guidelines of the National Institutes of Health. No human research subjects were involved in this study.

\section{Consent for publication}

Not applicable.

\section{Competing interests}

The authors declare that they have no competing interests.

\section{Author details}

'Department of Neurochemistry, Inge Grundke-lqbal Research Floor, New York State Institute for Basic Research in Developmental Disabilities, Staten Island, New York, USA. ${ }^{2}$ Key Laboratory of State Administration of Traditional Chinese Medicine of China, Department of Pathophysiology, School of Medicine, Institute of Brain Research, Jinan University, Guangzhou, China. ${ }^{3}$ Department of Pharmacology, School of Pharmaceutical Sciences, Guangzhou Medical University, Guangzhou, China.
Received: 26 February 2020 Accepted: 10 August 2020

Published online: 27 August 2020

\section{References}

1. Iqbal K, Grundke-lqbal I. Alzheimer's disease, a multifactorial disorder seeking multitherapies. Alzheimer's Dement. 2010;6(5):420-4.

2. Iqbal K, Grundke-lqbal I. Opportunities and challenges in developing Alzheimer disease therapeutics. Acta Neuropathol. 2011;122(5):543-9.

3. Alzheimer's A. 2016 Alzheimer's disease facts and figures. Alzheimer's Dement. 2016;12(4):459-509.

4. Hebert LE, Weuve J, Scherr PA, Evans DA. Alzheimer disease in the United States (2010-2050) estimated using the 2010 census. Neurology. 2013;80(19): 1778-83.

5. Scheltens P, Blennow K, Breteler MM, de Strooper B, Frisoni GB, Salloway S, Van der Flier WM. Alzheimer's disease. Lancet. 2016:388(10043):505-17.

6. Winblad B, Amouyel P, Andrieu S, Ballard C, Brayne C, Brodaty H, CedazoMinguez A, Dubois B, Edvardsson D, Feldman H, et al. Defeating Alzheimer's disease and other dementias: a priority for European science and society. Lancet Neurol. 2016;15(5):455-532.

7. Glenner GG, Wong CW. Alzheimer's disease: initial report of the purification and characterization of a novel cerebrovascular amyloid protein. Biochem Biophys Res Commun. 1984;120(3):885-90.

8. Grundke-lqbal I, Iqbal K, Tung YC, Quinlan M, Wisniewski HM, Binder LI. Abnormal phosphorylation of the microtubule-associated protein tau (tau) in Alzheimer cytoskeletal pathology. Proc Natl Acad Sci U S A. 1986:83(13):4913-7.

9. Alonso AC, Zaidi T, Grundke-lqbal I, Iqbal K. Role of abnormally phosphorylated tau in the breakdown of microtubules in Alzheimer disease. Proc Natl Acad Sci U S A. 1994;91(12):5562-6.

10. Li B, Chohan MO, Grundke-lqbal I, lqbal K. Disruption of microtubule network by Alzheimer abnormally hyperphosphorylated tau. Acta Neuropathol. 2007;113(5):501-11.

11. Spires-Jones TL, Hyman BT. The intersection of amyloid beta and tau at synapses in Alzheimer's disease. Neuron. 2014;82(4):756-71.

12. Heneka MT, Carson MJ, El Khoury J, Landreth GE, Brosseron F, Feinstein DL, Jacobs AH, Wyss-Coray T, Vitorica J, Ransohoff RM, et al. Neuroinflammation in Alzheimer's disease. Lancet Neurol. 2015:14(4):388-405.

13. Bateman RJ, Xiong C, Benzinger TL, Fagan AM, Goate A, Fox NC, Marcus DS, Cairns NJ, Xie X, Blazey TM, et al. Clinical and biomarker changes in dominantly inherited Alzheimer's disease. N Engl J Med. 2012;367(9):795-804.

14. Maruyama M, Shimada $H$, Suhara $T$, Shinotoh $H$, Ji B, Maeda J, Zhang MR, Trojanowski JQ, Lee VM, Ono M, et al. Imaging of tau pathology in a tauopathy mouse model and in Alzheimer patients compared to normal controls. Neuron. 2013;79(6):1094-108.

15. Frisardi V, Solfrizzi V, Imbimbo PB, Capurso C, D'Introno A, Colacicco AM, Vendemiale G, Seripa D, Pilotto A, Capurso A, et al. Towards diseasemodifying treatment of Alzheimer's disease: drugs targeting beta-amyloid. Curr Alzheimer Res. 2010;7(1):40-55.

16. Panza F, Solfrizzi V, Frisardi V, Capurso C, D'Introno A, Colacicco AM, Vendemiale G, Capurso A, Imbimbo BP. Disease-modifying approach to the treatment of Alzheimer's disease: from alpha-secretase activators to gammasecretase inhibitors and modulators. Drugs Aging. 2009:26(7):537-55.

17. Nagahara AH, Merrill DA, Coppola G, Tsukada S, Schroeder BE, Shaked GM, Wang L, Blesch A, Kim A, Conner JM, et al. Neuroprotective effects of brainderived neurotrophic factor in rodent and primate models of Alzheimer's disease. Nat Med. 2009;15(3):331-7.

18. Mitre M, Mariga A, Chao MV. Neurotrophin signalling: novel insights into mechanisms and pathophysiology. Clin Sci. 2017:131(1):13-23.

19. Huang EJ, Reichardt LF. Neurotrophins: roles in neuronal development and function. Annu Rev Neurosci. 2001;24:677-736.

20. Bolognin S, Buffelli M, Puolivali J, lqbal K. Rescue of cognitive-aging by administration of a neurogenic and/or neurotrophic compound. Neurobiol Aging. 2014;35(9):2134-46.

21. Khatoon S, Chalbot S, Bolognin S, Puolivali J, Iqbal K. Elevated tau level in aged rat cerebrospinal fluid reduced by treatment with a neurotrophic compound. J Alzheimer's Dis. 2015;47(3):557-64.

22. Li B, Wanka L, Blanchard J, Liu F, Chohan MO, labal K, Grundke-lqbal I. Neurotrophic peptides incorporating adamantane improve learning and memory, promote neurogenesis and synaptic plasticity in mice. FEBS Lett. 2010;584(15):3359-65. 
23. Kazim SF, Blanchard J, Dai CL, Tung YC, LaFerla FM, lqbal IG, Iqbal K. Disease modifying effect of chronic oral treatment with a neurotrophic peptidergic compound in a triple transgenic mouse model of Alzheimer's disease. Neurobiol Dis. 2014;71:110-30.

24. Perera F, Herbstman J. Prenatal environmental exposures, epigenetics, and disease. Reprod Toxicol. 2011;31(3):363-73.

25. Morris JA, Jordan CL, Breedlove SM. Sexual differentiation of the vertebrate nervous system. Nat Neurosci. 2004;7(10):1034-9.

26. Kazim SF, Blanchard J, Bianchi R, lqbal K. Early neurotrophic pharmacotherapy rescues developmental delay and Alzheimer's-like memory deficits in the Ts65Dn mouse model of Down syndrome. Sci Rep. 2017;7:45561.

27. Strupp BJ, Powers BE, Velazquez R, Ash JA, Kelley CM, Alldred MJ, Strawderman M, Caudill MA, Mufson EJ, Ginsberg SD. Maternal choline supplementation: a potential prenatal treatment for Down syndrome and Alzheimer's disease. Curr Alzheimer Res. 2016;13(1):97-106.

28. Herring A, Donath A, Yarmolenko M, Uslar E, Conzen C, Kanakis D, Bosma C, Worm K, Paulus W, Keyvani K. Exercise during pregnancy mitigates Alzheimer-like pathology in mouse offspring. FASEB J. 2012;26(1):117-28.

29. Blanchard J, Wanka L, Tung YC, Cardenas-Aguayo Mdel C, LaFerla FM, Iqbal K, Grundke-lqbal I. Pharmacologic reversal of neurogenic and neuroplastic abnormalities and cognitive impairments without affecting Abeta and tau pathologies in 3xTg-AD mice. Acta Neuropathol. 2010;120(5):605-21.

30. Chohan MO, Li B, Blanchard J, Tung YC, Heaney AT, Rabe A, lqbal K, Grundke-lqbal I. Enhancement of dentate gyrus neurogenesis, dendritic and synaptic plasticity and memory by a neurotrophic peptide. Neurobiol Aging 2011;32(8):1420-34.

31. Oddo S, Caccamo A, Kitazawa M, Tseng BP, LaFerla FM. Amyloid deposition precedes tangle formation in a triple transgenic model of Alzheimer's disease. Neurobiol Aging. 2003;24(8):1063-70.

32. Billings LM, Oddo S, Green KN, McGaugh JL, LaFerla FM. Intraneuronal Abeta causes the onset of early Alzheimer's disease-related cognitive deficits in transgenic mice. Neuron. 2005;45(5):675-88.

33. Carroll JC, Rosario ER, Kreimer S, Villamagna A, Gentzschein E, Stanczyk FZ, Pike CJ. Sex differences in beta-amyloid accumulation in 3xTg-AD mice: role of neonatal sex steroid hormone exposure. Brain Res. 2010;1366:233-45.

34. Clinton LK, Billings LM, Green KN, Caccamo A, Ngo J, Oddo S, McGaugh JL, LaFerla FM. Age-dependent sexual dimorphism in cognition and stress response in the 3xTg-AD mice. Neurobiol Dis. 2007;28(1):76-82.

35. Hirata-Fukae C, Li HF, Hoe HS, Gray AJ, Minami SS, Hamada K, Niikura T, Hua F, Tsukagoshi-Nagai H, Horikoshi-Sakuraba Y, et al. Females exhibit more extensive amyloid, but not tau, pathology in an Alzheimer transgenic model. Brain Res. 2008;1216:92-103.

36. Bevins RA, Besheer J. Object recognition in rats and mice: a one-trial nonmatching-to-sample learning task to study 'recognition memory'. Nat Protoc. 2006;1(3):1306-11.

37. Morris RG, Garrud P, Rawlins JN, O'Keefe J. Place navigation impaired in rats with hippocampal lesions. Nature. 1982;297(5868):681-3.

38. Vorhees CV, Williams MT. Morris water maze: procedures for assessing spatial and related forms of learning and memory. Nat Protoc. 2006;1(2): $848-58$

39. Greenberg SG, Davies P, Schein JD, Binder LI. Hydrofluoric acid-treated tau PHF proteins display the same biochemical properties as normal tau. J Biol Chem. 1992;267(1):564-9.

40. Vallet PG, Guntern R, Hof PR, Golaz J, Delacourte A, Robakis NK, Bouras C. A comparative study of histological and immunohistochemical methods for neurofibrillary tangles and senile plaques in Alzheimer's disease. Acta Neuropathol. 1992;83(2):170-8.

41. Kessels HW, Malinow R. Synaptic AMPA receptor plasticity and behavior. Neuron. 2009;61(3):340-50

42. Malenka RC, Bear MF. LTP and LTD: an embarrassment of riches. Neuron. 2004:44(1):5-21

43. Baazaoui N, Flory M, lqbal K. Synaptic compensation as a probable cause of prolonged mild cognitive impairment in Alzheimer's disease: implications from a transgenic mouse model of the disease. J Alzheimer's Dis. 2017;56(4):1385-401.

44. Baazaoui N, labal K. Prevention of dendritic and synaptic deficits and cognitive impairment with a neurotrophic compound. Alzheimers Res Ther. 2017;9(1):45

45. Kamenetz F, Tomita T, Hsieh H, Seabrook G, Borchelt D, Iwatsubo T, Sisodia S, Malinow R. APP processing and synaptic function. Neuron. 2003;37(6): 925-37.
46. Sze Cl, Troncoso JC, Kawas C, Mouton P, Price DL, Martin LJ. Loss of the presynaptic vesicle protein synaptophysin in hippocampus correlates with cognitive decline in Alzheimer disease. J Neuropathol Exp Neurol. 1997; 56(8):933-44.

47. Leyns CEG, Holtzman DM. Glial contributions to neurodegeneration in tauopathies. Mol Neurodegener. 2017;12(1):50.

48. Sofroniew MV, Vinters HV. Astrocytes: biology and pathology. Acta Neuropathol. 2010;119(1):7-35.

49. Emirandetti A, Graciele Zanon R, Sabha M Jr, de Oliveira AL. Astrocyte reactivity influences the number of presynaptic terminals apposed to spinal motoneurons after axotomy. Brain Res. 2006;1095(1):35-42.

50. Bockhorst KH, Narayana PA, Liu R, Ahobila-Vijjula P, Ramu J, Kamel M, Wosik J, Bockhorst T, Hahn K, Hasan KM, et al. Early postnatal development of rat brain: in vivo diffusion tensor imaging. J Neurosci Res. 2008;86(7):1520-8.

51. Catalani A, Sabbatini M, Consoli C, Cinque C, Tomassoni D, Azmitia E, Angelucci L, Amenta F. Glial fibrillary acidic protein immunoreactive astrocytes in developing rat hippocampus. Mech Ageing Dev. 2002;123(5): 481-90

52. Dekaban AS. Changes in brain weights during the span of human life: relation of brain weights to body heights and body weights. Ann Neurol. 1978:4(4):345-56.

53. Yang J, Harte-Hargrove LC, Siao CJ, Marinic T, Clarke R, Ma Q, Jing D, Lafrancois JJ, Bath KG, Mark W, et al. proBDNF negatively regulates neuronal remodeling, synaptic transmission, and synaptic plasticity in hippocampus. Cell Rep. 2014;7(3):796-806.

54. Guedj F, Sebrie C, Rivals I, Ledru A, Paly E, Bizot JC, Smith D, Rubin E, Gillet $B$, Arbones $\mathrm{M}$, et al. Green tea polyphenols rescue of brain defects induced by overexpression of DYRK1A. PLoS One. 2009;4(2):e4606.

55. Dogliotti G, Galliera E, Licastro F, Corsi MM. Age-related changes in plasma levels of BDNF in Down syndrome patients. Immun Ageing. 2010;7:2.

56. Castro P, Zaman S, Holland A. Alzheimer's disease in people with Down's syndrome: the prospects for and the challenges of developing preventative treatments. J Neurol. 2017;264(4):804-13.

57. Pasquin S, Sharma M, Gauchat JF. Ciliary neurotrophic factor (CNTF): new facets of an old molecule for treating neurodegenerative and metabolic syndrome pathologies. Cytokine Growth Factor Rev. 2015;26(5):507-15.

58. Kazim SF, lqbal K. Neurotrophic factor small-molecule mimetics mediated neuroregeneration and synaptic repair: emerging therapeutic modality for Alzheimer's disease. Mol Neurodegener. 2016;11(1):50.

59. Bolognin S, Blanchard J, Wang X, Basurto-Islas G, Tung YC, Kohlbrenner E, Grundke-lqbal I, Iqbal K. An experimental rat model of sporadic Alzheimer's disease and rescue of cognitive impairment with a neurotrophic peptide. Acta Neuropathol. 2012;123(1):133-51.

60. Sperling RA, Aisen PS, Beckett LA, Bennett DA, Craft S, Fagan AM, Iwatsubo T, Jack CR Jr, Kaye J, Montine TJ, et al. Toward defining the preclinical stages of Alzheimer's disease: recommendations from the National Institute on Aging-Alzheimer's Association workgroups on diagnostic guidelines for Alzheimer's disease. Alzheimer's Dement. 2011;7(3):280-92.

61. Albert MS, DeKosky ST, Dickson D, Dubois B, Feldman HH, Fox NC, Gamst A, Holtzman DM, Jagust WJ, Petersen RC, et al. The diagnosis of mild cognitive impairment due to Alzheimer's disease: recommendations from the National Institute on Aging-Alzheimer's Association workgroups on diagnostic guidelines for Alzheimer's disease. Alzheimer's Dement. 2011;7(3):270-9.

62. McKhann GM, Knopman DS, Chertkow H, Hyman BT, Jack CR Jr, Kawas $\mathrm{CH}$, Klunk WE, Koroshetz WJ, Manly JJ, Mayeux R, et al. The diagnosis of dementia due to Alzheimer's disease: recommendations from the National Institute on Aging-Alzheimer's Association workgroups on diagnostic guidelines for Alzheimer's disease. Alzheimer's Dement. 2011; 7(3):263-9.

63. Oddo S, Caccamo A, Shepherd JD, Murphy MP, Golde TE, Kayed R, Metherate R, Mattson MP, Akbari Y, LaFerla FM. Triple-transgenic model of Alzheimer's disease with plaques and tangles: intracellular Abeta and synaptic dysfunction. Neuron. 2003;39(3):409-21.

64. Selkoe DJ. Alzheimer's disease is a synaptic failure. Science. 2002; 298(5594):789-91

65. Gomez-Isla T, Price JL, McKeel DW Jr, Morris JC, Growdon JH, Hyman BT Profound loss of layer II entorhinal cortex neurons occurs in very mild Alzheimer's disease. J Neurosci. 1996;16(14):4491-500

66. Shankar GM, Walsh DM. Alzheimer's disease: synaptic dysfunction and Abeta. Mol Neurodegener. 2009;4:48. 
67. McGeer EG, McGeer PL. Neuroinflammation in Alzheimer's disease and mild cognitive impairment: a field in its infancy. J Alzheimer's Dis. 2010; 19(1):355-61.

68. Schwab C, Klegeris A, McGeer PL. Inflammation in transgenic mouse models of neurodegenerative disorders. Biochim Biophys Acta. 2010; 1802(10):889-902.

69. Kitazawa M, Oddo S, Yamasaki TR, Green KN, LaFerla FM. Lipopolysaccharide-induced inflammation exacerbates tau pathology by a cyclin-dependent kinase 5-mediated pathway in a transgenic model of Alzheimer's disease. J Neurosci. 2005;25(39):8843-53.

\section{Publisher's Note}

Springer Nature remains neutral with regard to jurisdictional claims in published maps and institutional affiliations.

Ready to submit your research? Choose BMC and benefit from:

- fast, convenient online submission

- thorough peer review by experienced researchers in your field

- rapid publication on acceptance

- support for research data, including large and complex data types

- gold Open Access which fosters wider collaboration and increased citations

- maximum visibility for your research: over $100 \mathrm{M}$ website views per year

At BMC, research is always in progress.

Learn more biomedcentral.com/submissions 